\title{
An Experimental Study on Modification of Dense Graded Bituminous Mix Design
}

\author{
Vineet Jain \\ Asst. Professor, Civil Engineering \\ Department, Smt. S. R. Patel \\ Engineering College Unjha, \\ Gujarat
}

\author{
Utkarsh Nigam \\ Asst. Professor, Civil Engineering \\ Department, Smt. S. R. Patel \\ Engineering College Unjha, \\ Gujarat
}

\author{
Lokesh Gupta \\ Asst. Professor, \\ Sir Padampat Singhania University \\ Udaipur, \\ Rajasthan
}

\section{ABSTRACT}

Various problems on the roads have been frequently observed on flexible pavements like: potholes, rutting, shoving etc. In hot and developing countries like India, roads are affected by severed problems mentioned above, due to the water presence in the pavement, heavy traffic load, excessive no. of vehicles. Literature review lightens up on solution of these problems by modification of bitumen. To lighten this process, several measures may be effective, such as, use of better quality materials like waste plastic, motor oil, crumb rubber. This study proposes the utilization of waste materials i.e. waste plastic, crumb rubber and motor oil and check their suitability to mitigate theses defects of cracking, rutting, pothole etc. Marshal stability method is chosen to determine the stability and flow value for bitumen mix design. Individual effects of polythene, crumb rubber and motor oil is analyzed first by varying the percentage of same with optimum bitumen content. And comprehensive effect of these three material has been also observed and discussed by plotting the graphs and it is found that Bitumen (5.5\%), Crumb Rubber (8\%), Waste Plastic (6\%) and Motor Oil (2\%) gives highest stability and other properties values within the range given in MORTH. It is expected that this study would be useful to researchers and consultancies to construct the roads economically and long lasting servicing.

\section{KEYWORD}

DBM, Plastic, Motor Oil, Crumb Rubber, Mix Design

\section{INTRODUCTION}

At a very long time there is problem of releasing of fine aggregate particles. Strength and functional problems like cracks on road, flexibility, durability of road is occur after some years. The normal roads are not more stable and resistible to the climate changes, therefore there is a need to mitigate these problems. Therefore, this study identifies need to improve the bituminous mix design to recover the problems mentioned above. Need to modify the property of bitumen by using this modifier. The use of waste polythene material has received a boost in the field of road construction. However the huge quantity of waste polythene disposal becomes a great problem to the country. Further increasing waste tyre disposal causes hazardous problems that lead environmental pollution. Therefore, use of waste tyre can be helpful in modification of bitumen mix in enhancing pavement life, driving comfort and low maintenance. Based on literature review it has been observed that the effect of bitumen modification using waste tyre is worth full but not at its full efficiency due to reduction in flow value of bitumen mix. Therefore, waste motor oil is introduced to enhance the lubrication property of bitumen mix, so that bitumen mix can be modified economically with its full efficiency. Thus, the effect of modifiers i.e. crumb rubber, waste plastic and waste motor oil is investigated in this study in comprehensive manner. Initially the effect of crumb rubber $\%$ is evaluated starting from $4 \%$ and increment is done by $2 \%$ and properties of bitumen mix are evaluated up to $10 \%$. Results obtained from marshall stability is found that $8 \%$ of crumb rubber gives better results in stability and within permissible limits defined by MORTH. Secondly the effect of plastic \% is evaluated starting from $4 \%$ and increment is done by $2 \%$ and properties of bitumen mix are evaluated up to $10 \%$. Results obtained from marshall stability is found that $8 \%$ of plastic gives better results in stability and within permissible limits defined by MORTH. Thirdly the effect of waste motor oil percentage is evaluated starting from $4 \%$ and increment is done by $2 \%$ and properties of bitumen mix is evaluated up to $8 \%$. Results obtained from 
Marshall stability does not show improvement in stability. However, it is expected that comprehensive use of motor oil with rubber and plastic will improve the results. Finally variation of all modifiers are checked by conducting marshall stability test and it is found that Bitumen (5.5\%), Crumb Rubber (8\%), Waste Plastic (6\%) and Motor Oil (2\%) gives highest stability and other properties values within the range given in MORTH The main objective of the study is to analyse the performance of modified bitumen mix design by using motor oil, waste plastic, crumb rubber. To determine the relevant index and engineering properties of plastic waste, rubber tyre and compare them with conventional bitumen.

\section{LITERATURE REVIEW}

A typical literature is carried out on the modifying bitumen mix design by using various waste materials or combination of waste material. Magdy abdelrahman et.al. (2015) found that the utilization of UMO only as a modifier to asphalt severely deteriorates the macro and micro mechanical properties of the binder because the UMO disrupts the asphalt intermolecular associations and internal network structure, in the absence of CRM. Combining CRM with UMO as modifiers to asphalt had better results for the lower percentages of modifiers $(10 \%$ CRM with 3\% UMO). Niraj D.et.al. (2013). K. Rajesh Kumar (2014), Rishi Singh Chhabra et. Al. (2014) alos studied on effects of crumb rubber and HDPE on bituminous mix design. Optimum substance of waste elastic tires to be utilized is between the scope of 5\% to $20 \%$. Problem like warm breaking and perpetual distortion are diminish in hot temperature area. Use of waste polyethylene in HMA is relied upon to yield better and improved waste administration and better city cleanliness and environment. Athira R Prasad (2015) conducted a study by completing Marshall Test for control blend tests which was set up by including $5 \%, 5.5 \%, 6 \%, 6.5 \%, 7 \%$ bitumen by weight of total to shape $\mathrm{BC}$ blend, $\mathrm{OBC}$ was gotten as $5.1 \%$. Addition of PET and elastic in 3\%, 4.5\%, 6\%, $7.5 \%$ and $9 \%$ to $\mathrm{BC}$ blend tests keeping steady OBC. It was found that in every one of the three cases, the ideal substance was acquired as $6 \%$.

\section{FRAME WORK OF METHODOLOGY}

Fig 1 shows that for proposed details of the steps involved in the frame work of proposed methodology and the detail of the steps are given as below in the subsections.

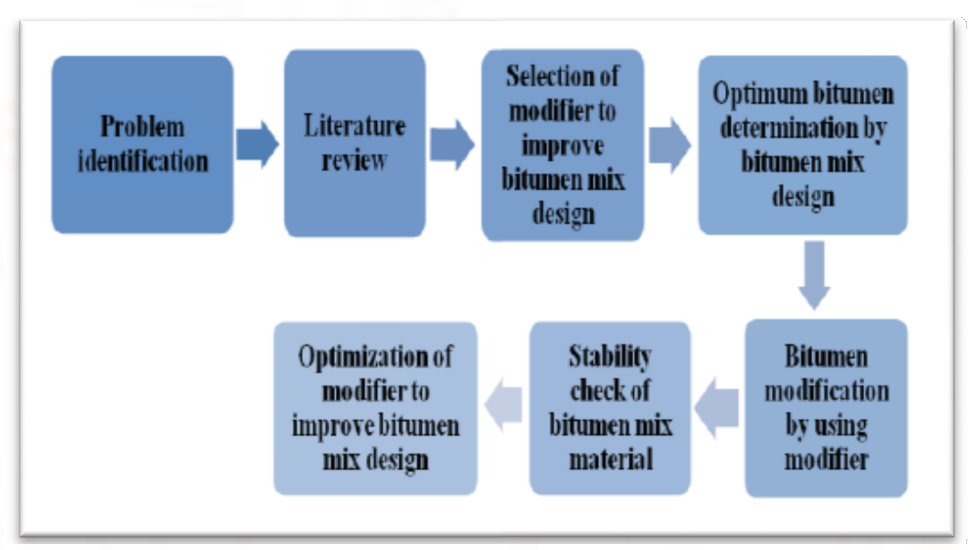

Fig 1:Frame work of proposed methodology

\section{Steps Involved in Proposed Methodology}

$>$ Selection of modifiers to improve bituminous mix design

$>$ Suitability check of bitumen mix material

$>$ Optimum bitumen determination by bitumen mix design

$>$ Bitumen modification by using modifiers

$>$ Optimization of modifiers to improve bitumen mix design

\section{RESULTS AND ANALYSIS}

\section{A. Selection of modifiers to improve bituminous mix design}

\section{Crumb Rubber}

Increasing number of four wheeler and two wheeler resulting huge amount of waste tyre that is disposed in rural as well as in urban areas. Disposed tyres are creating environmental hazardous problems by open burning tyres.

\section{Waste Plastic}

Waste plastics collected from households are washed, cleaned and dried. Polythenes shredded into small pieces in required quantities to blend with hot bitumen at $170-1800 \mathrm{C}$ for around 30 minutes. Percentage variation in terms of weightage of bitumen. 


\section{Waste Motor Oil}

Waste motor oil is additional modifier is tried in this study to enhance flow value of bitumen mix. Understanding of decreasing value of flow value due to increase of crumb rubber fails the suitable results of Mix design.

\section{B. Suitability check of bitumen mix material}

TABLE I TEST RESULTS FOR AGGREGATE

\begin{tabular}{|l|l|l|l|l|}
\hline \multicolumn{1}{|c|}{ Test } & Sample 1 & $\begin{array}{c}\text { Sample } \\
\mathbf{2}\end{array}$ & Average & $\begin{array}{c}\text { Optimu } \\
\text { m value } \\
\text { of test }\end{array}$ \\
\hline $\begin{array}{l}\text { Impact } \\
\text { value }\end{array}$ & 6.17 & 3.99 & 5.08 & $<35 \%$ \\
\hline $\begin{array}{l}\text { Elongation } \\
\text { flakiness } \\
\text { index(\%) }\end{array}$ & 13.11 & 16.94 & 30.05 & $\begin{array}{l}\text { Combine } \\
\mathrm{d}<40 \%\end{array}$ \\
\hline $\begin{array}{l}\text { Loss } \\
\text { angeles } \\
(\%)\end{array}$ & 10.84 & 13.04 & 11.94 & $<50 \%$ \\
\hline
\end{tabular}

TABLE III TEST RESULTS FOR BITUMEN

\begin{tabular}{|l|l|l|l|l|}
\hline \multicolumn{1}{|c|}{ Test } & $\begin{array}{c}\text { Sample } \\
\mathbf{1}\end{array}$ & \multicolumn{1}{c|}{$\begin{array}{c}\text { Sample } \\
\mathbf{2}\end{array}$} & \multicolumn{1}{|c|}{$\begin{array}{c}\text { Sample } \\
\mathbf{3}\end{array}$} & Average \\
\hline $\begin{array}{l}\text { Softening } \\
\text { point }\left({ }^{\circ} \mathrm{C}\right)\end{array}$ & 48 & 51 & 53 & 50.33 \\
\hline $\begin{array}{l}\text { Penetration } \\
(\mathrm{mm})\end{array}$ & 24.3 & 27.9 & 29.5 & 27.23 \\
\hline $\begin{array}{l}\text { Ductility } \\
(\mathrm{cm})\end{array}$ & 47.4 & 49.7 & - & 48.55 \\
\hline $\begin{array}{l}\text { Flash point }\left({ }^{\circ} \mathrm{C}\right) \\
\text { Fire point }\end{array}$ & 251 & 249 & 248 & 249.33 \\
\hline \begin{tabular}{l}
$\left.{ }^{\circ} \mathrm{C}\right)$ \\
\hline
\end{tabular} & 266 & 263 & 261 & 263.33 \\
\hline
\end{tabular}

\section{Optimum bitumen determination by bitumen mix design}

Dense Graded Bituminous Macadam grading has been selected in this study to modify the bitumen mix design. Aggregate Grading given in Table III is selected from MORTH- 500, 5th revision Specifications for DBM Grade. Bitumen having penetration grade $60 / 70$ has been selected in this study, generally suitable for superior properties of flexible pavements. Marshal Stability Testing of Bitumen mix is used to check the properties of bitumen mix i.e. marshal stability, flow value, air voids etc.

Marshal test is used to determine the optimum bitumen content for a designed bitumen mix. Optimum bitumen is the content of bitumen at which mix satisfies the mechanical and volumetric properties of bitumen mix. Fig 2 shows the process of marshal stability test from starting grading of aggregates to testing to determine stability and flow value.

\section{TABLE IIIII TABLE OF GRADING OF AGGREGATE}

\begin{tabular}{|c|c|c|}
\hline Grading & 1 & 2 \\
\hline $\begin{array}{l}\text { Nominal aggregate } \\
\text { size* }\end{array}$ & $37.5 \mathrm{~mm}$ & $26.5 \mathrm{~mm}$ \\
\hline Layer thickness & $75-100 \mathrm{~mm}$ & $50-75 \mathrm{~mm}$ \\
\hline \multicolumn{3}{|c|}{ IS Sieve (mm) Cumulative $\%$ by weight of total aggregate passing } \\
\hline 45 & 100 & - \\
\hline 37.5 & $95-100$ & 100 \\
\hline 26.5 & $63-93$ & $90-100$ \\
\hline 19 & - & $71-95$ \\
\hline 13.2 & $55-75$ & $56-80$ \\
\hline 9.5 & - & - \\
\hline 4.75 & $38-54$ & $38-54$ \\
\hline 2.36 & $28-42$ & $38-54$ \\
\hline 1.18 & - & - \\
\hline 0.6 & - & - \\
\hline 0.3 & $7-21$ & $7-21$ \\
\hline 0.15 & - & - \\
\hline 0.075 & $2-8$ & $7-21$ \\
\hline $\begin{array}{l}\text { Bitumen content } \% \text { by } \\
\text { mass of total mix } * *\end{array}$ & $\operatorname{Min} 4.0$ & $\operatorname{Min} 4.5$ \\
\hline
\end{tabular}

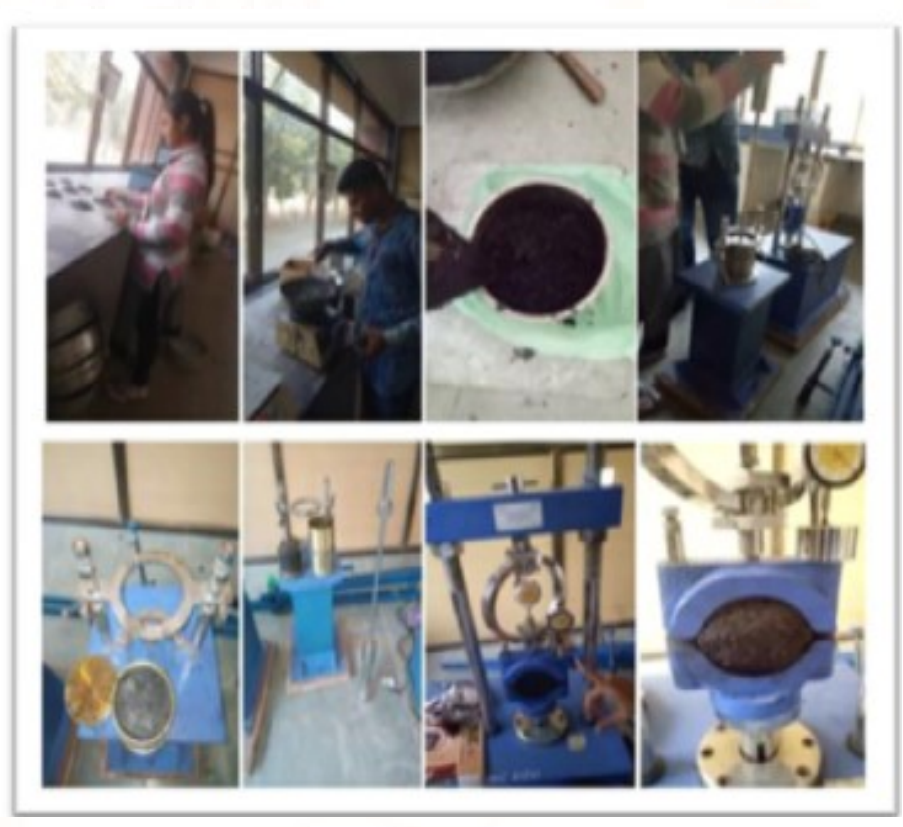

Fig 2:Bitumen Mix Design Process to Find OBC for DBM 


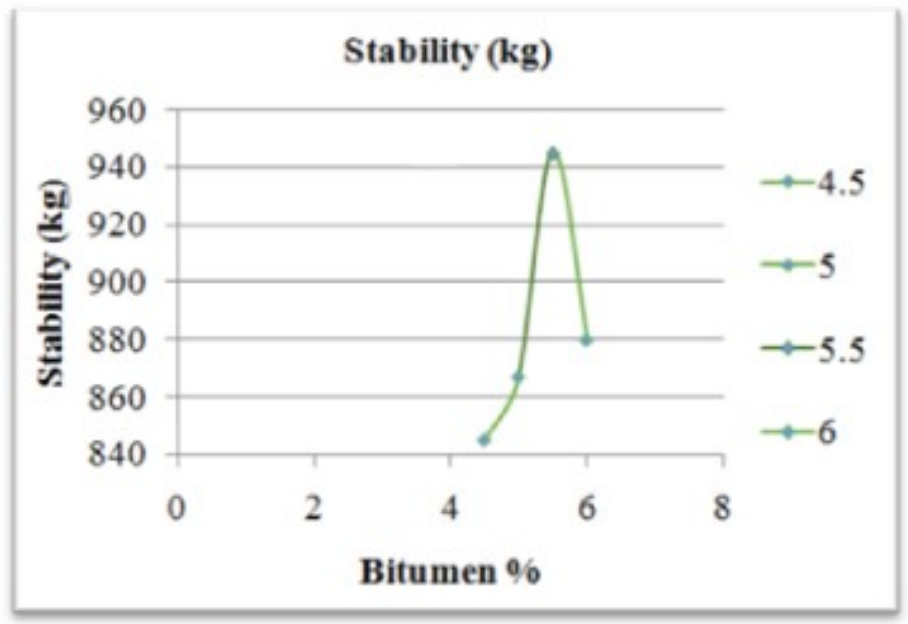

Fig 3 Graph showing Stability v/s Bitumen Content \%

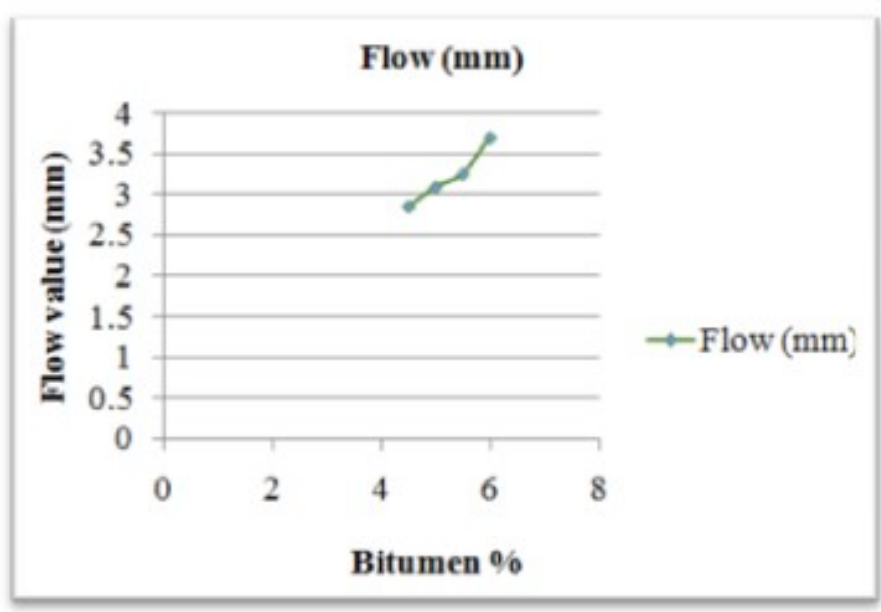

Fig 4 Graph showing Flow value v/s Bitumen Content \%

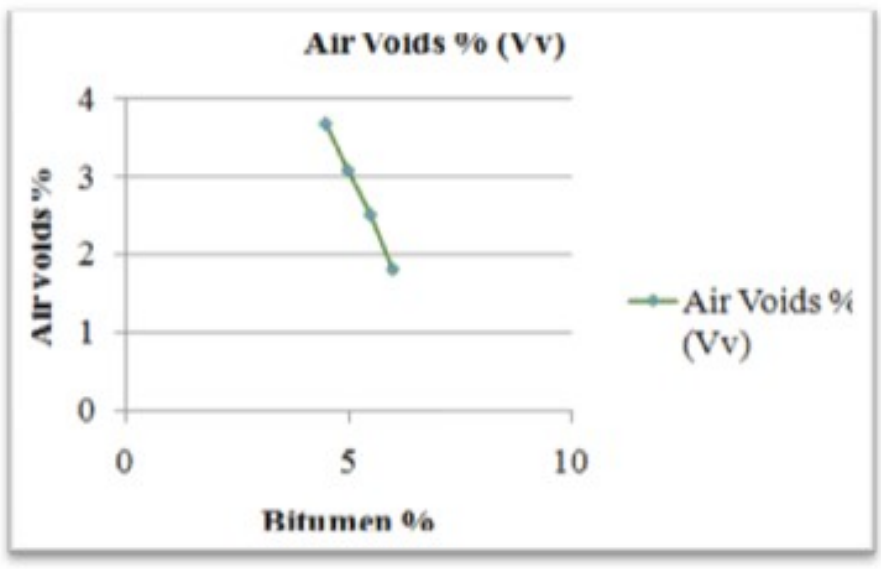

Fig 5 Graph showing Air Voids v/s Bitumen Content \%

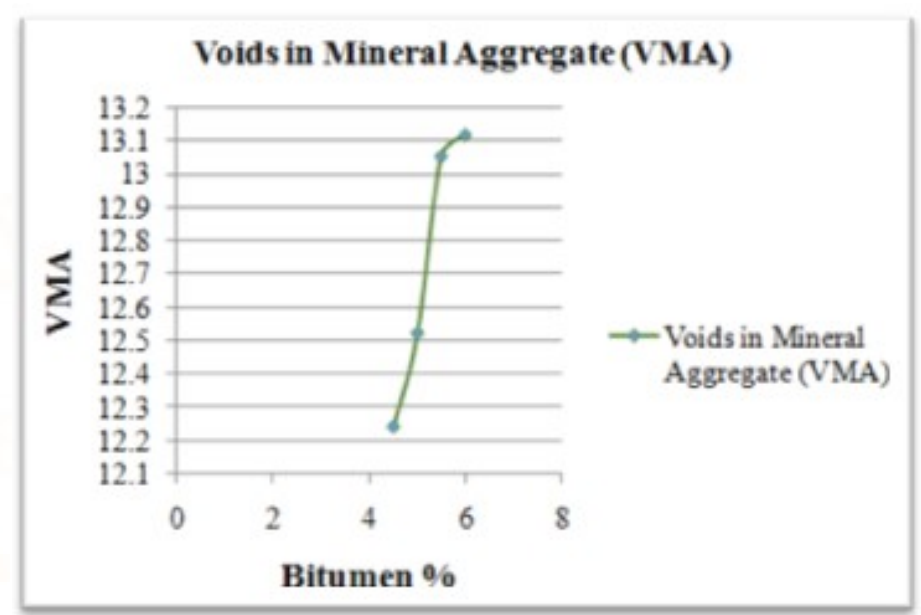

Fig 6 Graph showing VMA v/s Bitumen Content \%

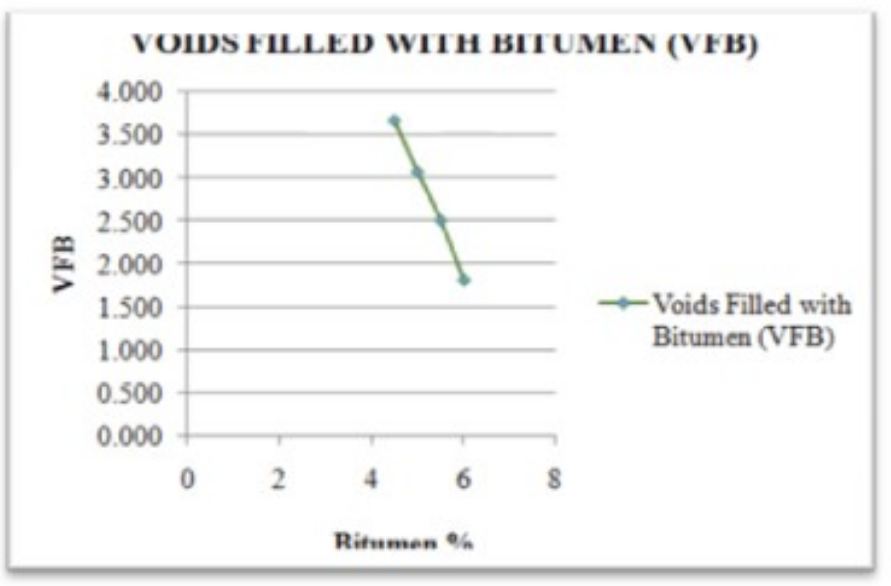

Fig 7 Graph showing VFB v/s Bitumen Content \%

A bituminous mix sample is prepared by adding $\%$ of bitumen starting from $4.5 \%$ to $6.0 \%$. The results of flow value and stability value is obtained and shown in the Fig3 and Fig 4 above. As per the graph plotted the flow value is increasing as the bitumen content increasing but stability value decrease after $5.5 \%$ of bitumen content. Therefore from the graph Optimum Bitumen Content is found as $5.5 \%$. 


\section{Bitumen modification by using modifiers}

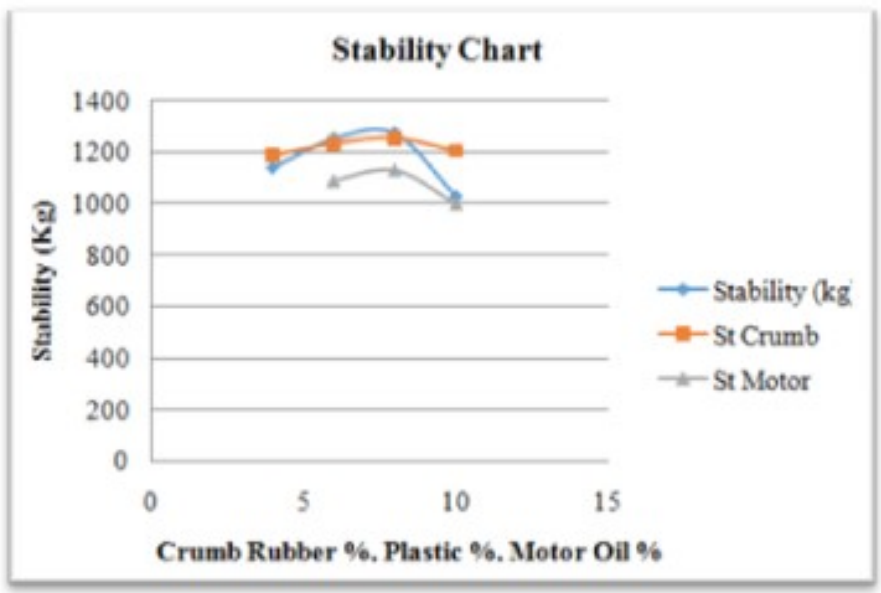

Fig 8 Graph showing marshal stability v/s modifiers: crumb rubber, plastic and motor oil

It is clear out from the graphs that with the variation of plastic, motor oil, and crumb rubber stability value changes. Crumb rubber is most effective in enhancing the stability value compared to motor oil and plastic.

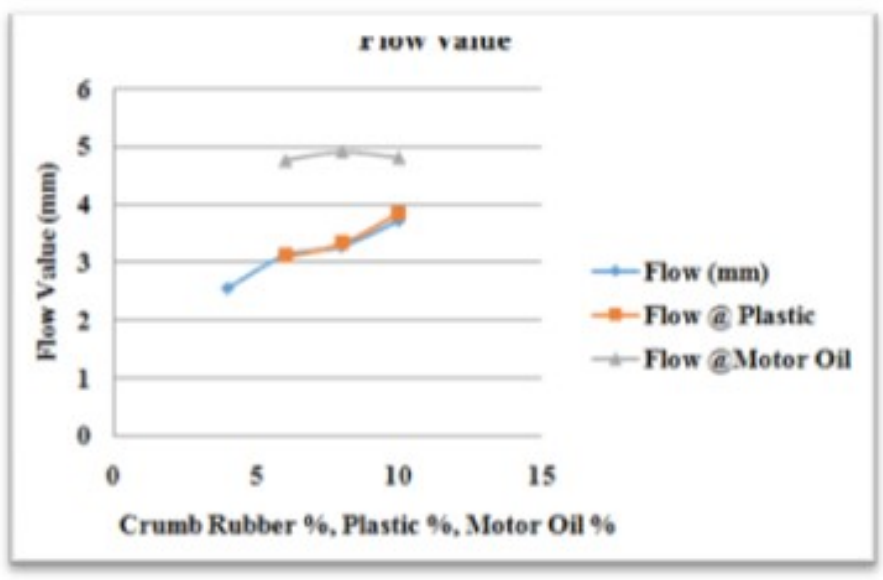

Fig 9 Graph of Flow value v/s modifiers

Flow value is higher with motor oil as compare to other materials and flow value increases with percentage of material.

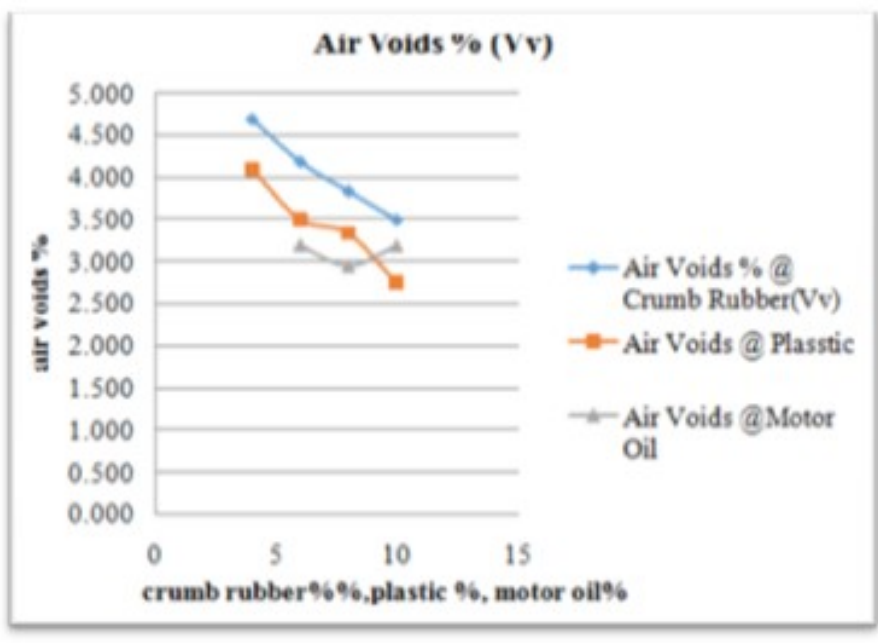

Fig 10 Graph showing air voids v/s modifiers: crumb rubber, plastic and motor oil

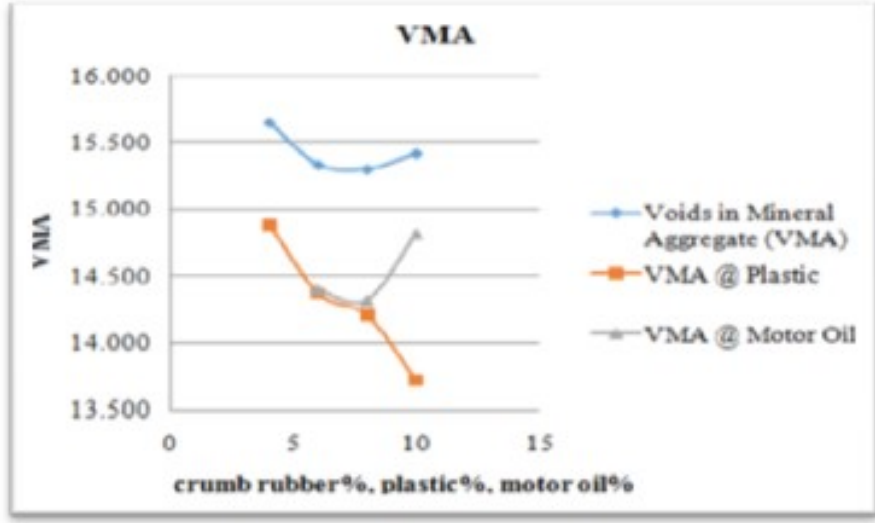

Fig 11 Graph showing VMA v/s modifiers: crumb rubber, plastic and motor oil

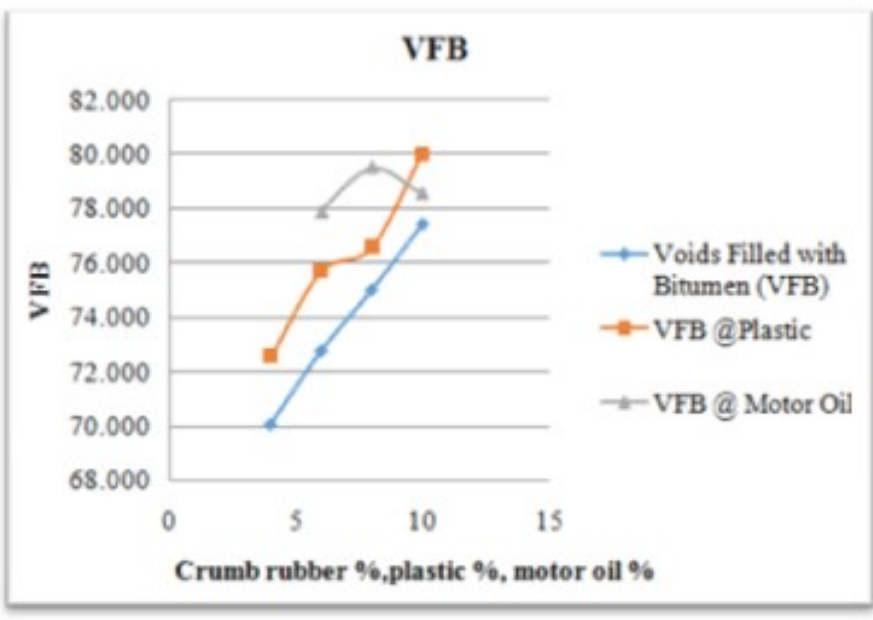

Fig 12 Graph showing VMA v/s modifiers: crumb rubber, plastic and motor oil 
Finally variation of all modifiers are checked by conducting marshall stability test and it is found that Bitumen (5.5\%), Crumb Rubber (8\%), Waste Plastic $(6 \%)$ and Motor Oil (2\%) gives highest stability and other properties values within the range given in MORTH. It is expected that this study would be useful to construction roads economically and ecofriendly.

\section{CONCLUSIONS}

In the road construction potholes, rutting, shoving are created due the environment problems. This problems can be mitigate by modifying bitumen. Based on literature review, it is found that comprehensive effects of rubber, motor oil and plastic have not been done. Therefore, this study proposed a methodology to improve the bitumen mix design by using combined modifiers waste plastic, waste motor oil, waste tyre crumb. Methodology consists total six stages. Determination of optimum bitumen is founded by conduct marshal stability which is $5.5 \%$ of total amount of aggregate. After optimum bitumen content, optimum percentage of modifiers would be found. Initially the effect of crumb rubber $\%$ is evaluated starting from $4 \%$ and increment is done by $2 \%$ and properties of bitumen mix are evaluated up to $10 \%$. Results obtained from marshall stability is found that $8 \%$ of crumb rubber gives better results in stability and within permissible limits defined by MORTH. Secondly the effect of plastic \% is evaluated starting from $4 \%$ and increment is done by $2 \%$ and properties of bitumen mix are evaluated up to $10 \%$. Results obtained from marshall stability is found that $8 \%$ of plastic gives better results in stability and within permissible limits defined by MORTH. Thirdly the effect of waste motor oil percentage is evaluated starting from $4 \%$ and increment is done by $2 \%$ and properties of bitumen mix is evaluated up to $8 \%$. Results obtained from Marshall stability does not show improvement in stability. However, it is expected that comprehensive use of motor oil with rubber and plastic will improve the results. Finally variation of all modifiers are checked by conducting marshall stability test and it is found that Bitumen (5.5 $\%)$, Crumb Rubber (8\%), Waste Plastic (6\%) and Motor Oil (2\%) gives highest stability and other properties values within the range given in MORTH. It is expected that this study would be useful to construction roads economically and eco friendly.

\section{REFERENCES}

[1] (-Rishi singh chabbra, supriya malik\|) (2014) (-A Review Literature on The Use of Waste Plastics And Waste Rubber Tyres In Pavementl) (-International Journal of Core Management\|( IJCEM)

[2] (Maddy Abdelrahman,Mohyeldin Ragab And Daniel Bergerson) (-2015\|) (-Effect Of Used Motor Oil on the Macro and Micromechanical properties of Crumb Rubber Modified Asphalt\|) (-International Journal of Waste Resourcesll).

[3] (Niraj D. Baraiya) (2013) (Use of Waste Rubber Tyres In construction of Bituminous Road - An Overview) (International JOURNAL of APPLICATION or Innovation in Engineering \& Management

(IJAIEM)).

[4] (K.Rajesh Kumar , Dr, N. Mahendran) (2014) (Experimental Studies on Modified Bituminous mixes Using Waste HDPE and Crumb Rubber) (International Journal of Advanced Engineering (IJETAE)).

[5] (-Pradeep Soyall) (2015) (-Use of Waste Polythene in bituminous concrete mix \|) (-International Research Journal of Engineering and technology\|( ISSN $2395 \quad$ 0056) ).

[6] (Nabin Rana Magar) (-2014\|) (-A Study on Performances of Crumb Rubber Modified Bitumen by varying the Size of Crumb Rubberll) (-International Journal of Engineering Trends and Technologyll)ISSN 22315381.

[7] (Rokade S.) (2012) (Use of Waste Plastic and Waste Rubber Tyres In Flexible Pavements) (International Conference on Future Environment and Energy)

[8] (Swant P A, Kulkarni S S) (2014) (Comparative Study of Bitumenous mix Modified by EVA and Crumb Rubber ) (International Journal on Recent and Innovation Trends in Computing and Communication ISSN 2321 - 8689)). 